\title{
Acute lower limb ischaemia
}

\author{
R.S. Young ${ }^{1}$, C. Chang ${ }^{1}$, P. Walker ${ }^{2}$, S. Vanniasinkam \\ 1 Leeds Vascular Institute, \\ 2 Department of Interventional Radiology, \\ Leeds General Infirmary, Great George Street, Leeds, United Kingdom LS1 3EX
}

Key words: Acute; limb; ischaemia; revascularisation

\section{Introduction}

Acute limb ischaemia (ALI) is defined as a sudden reduction in limb perfusion that results in a potential threat to limb viability. Symptoms must be present for less than 2 weeks although within this timeframe a range of presentations will be encountered [1]. Broadly, this will include those with a few hours of symptoms and a classically ischaemic limb with motor and sensory neurological signs, patients with short distance claudication and others with a marked deterioration in previously stable chronic limb ischaemia. The proportion in the final category will continue to increase both as populations age, with a higher population prevalence of peripheral arterial disease, and as cardiogenic sources of emboli responsible for classical ALI become increasingly rare [2].

\section{Materials and methods}

The classical "6 Ps" of ALI remain important but may be less pronounced if patients background chronic arterial disease. Nevertheless, the fundamental importance of prompt recognition of these classical features cannot be underestimated: pain, pallor, pulselessness, paraesthesia, perishingly cold and paralysis.

Full cardiovascular examination and assessment to exclude important differential diagnoses must be undertaken, Box 1.

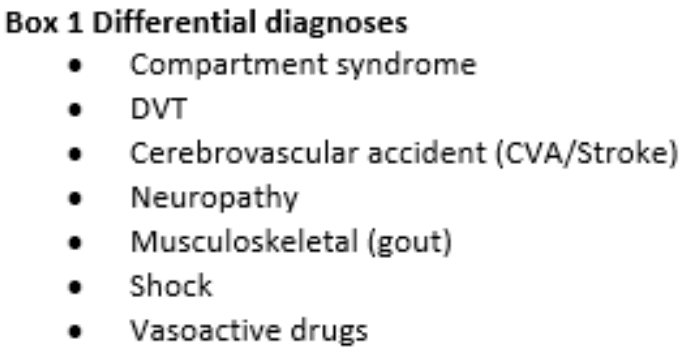

Correspondence: R.S. Young

E-mail: richard.young10@nhs.net

Received: 08-12-2016 Accepted: 05-02-2017

(iD) http://orcid.org/0000-0002-0083-1942 DOI: http://doi.org/10.4038/sljs.v35i1.8347 (cc)BY
Doppler assessment of pulses and calculation of the ankle brachial pressure index (ABPI) is essential to help categorise the severity of ischaemia.

Once the assessment is complete and the diagnosis of ALI is established classification of the insult according to the Rutherford criteria is essential, Table 1 [3].

\section{Investigation}

Standard investigations should include an ECG to identify atrial fibrillation, standard blood panels and imaging. Once the need for and urgency of imaging has been established the modality is determined by local expertise. The aim is to define the nature and extent of the problem and plan intervention in a timely manner. Options include duplex USS (non-invasive, usually quickly available but operator dependent), CT or MR angiogram (non-invasive and provide anatomical road map but require nephrotoxic contrast) or conventional digital subtraction angiography (advantage of the ability to intervene).

\section{Management}

Treatment objectives differ between revascularisation, amputation and palliation dependent on timing of presentation, severity of ALI and performance status. Initial management includes analgesia, oxygen, intra venous fluids and anticoagulation. Further management is determined according to the Rutherford classification, Figure 1.

\section{Anticoagulation}

To prevent further thrombus propagation anticoagulation should be instigated whilst awaiting further investigations. However, if immediate revascularisation is a possibility under spinal/regional anaesthesia in high risk patients, this may be deferred until after neuraxial block [4].

Standard therapy involves the use of intravenous unfractionated heparin (UFH). The use of UFH allows relatively quick reversal of clotting function should intervention become indicated.

The main disadvantage of its use involves the frequency of

The Sri Lanka Journal of Surgery 2017; 35(1): 10-14 


\begin{tabular}{|l|l|l|l|l|l|}
\hline Grade & Sensory Loss & $\begin{array}{l}\text { Muscle } \\
\text { Weakness }\end{array}$ & $\begin{array}{l}\text { Arterial } \\
\text { Doppler }\end{array}$ & $\begin{array}{l}\text { Venous } \\
\text { Doppler }\end{array}$ & Investigations \\
\hline 1. Viable & - & - & Audible & Audible & Diagnostic imaging \\
\hline $\begin{array}{c}\text { 2. a. Threatened Salvageable } \\
\text { prompt intervention }\end{array}$ & $\begin{array}{l}\text { None/ minimal } \\
\text { (toes) }\end{array}$ & - & $\begin{array}{l}\text { Often } \\
\text { absent }\end{array}$ & Audible & $\begin{array}{l}\text { Diagnostic imaging urgently } \\
\text { (<24hrs })\end{array}$ \\
\hline $\begin{array}{c}\text { b. Threatened Salvageable } \\
\text { immediate intervention }\end{array}$ & $\begin{array}{l}\text { More than toes } \\
\text { with rest pain }\end{array}$ & $\begin{array}{l}\text { Mild/ } \\
\text { Moderate }\end{array}$ & $\begin{array}{l}\text { Usually } \\
\text { absent }\end{array}$ & Audible & $\begin{array}{l}\text { Diagnostic imaging } \\
\text { immediately or Hybrid } \\
\text { Theatre }\end{array}$ \\
\hline $\begin{array}{c}\text { 3. Irreversible Major tissue } \\
\text { loss or nerve damage inevitable }\end{array}$ & Insensate & $\begin{array}{l}\text { Profound/ } \\
\text { paralysed }\end{array}$ & Absent & Absent & Not required \\
\hline
\end{tabular}

Table 1. Rutherford classification of acute limb ischaemia

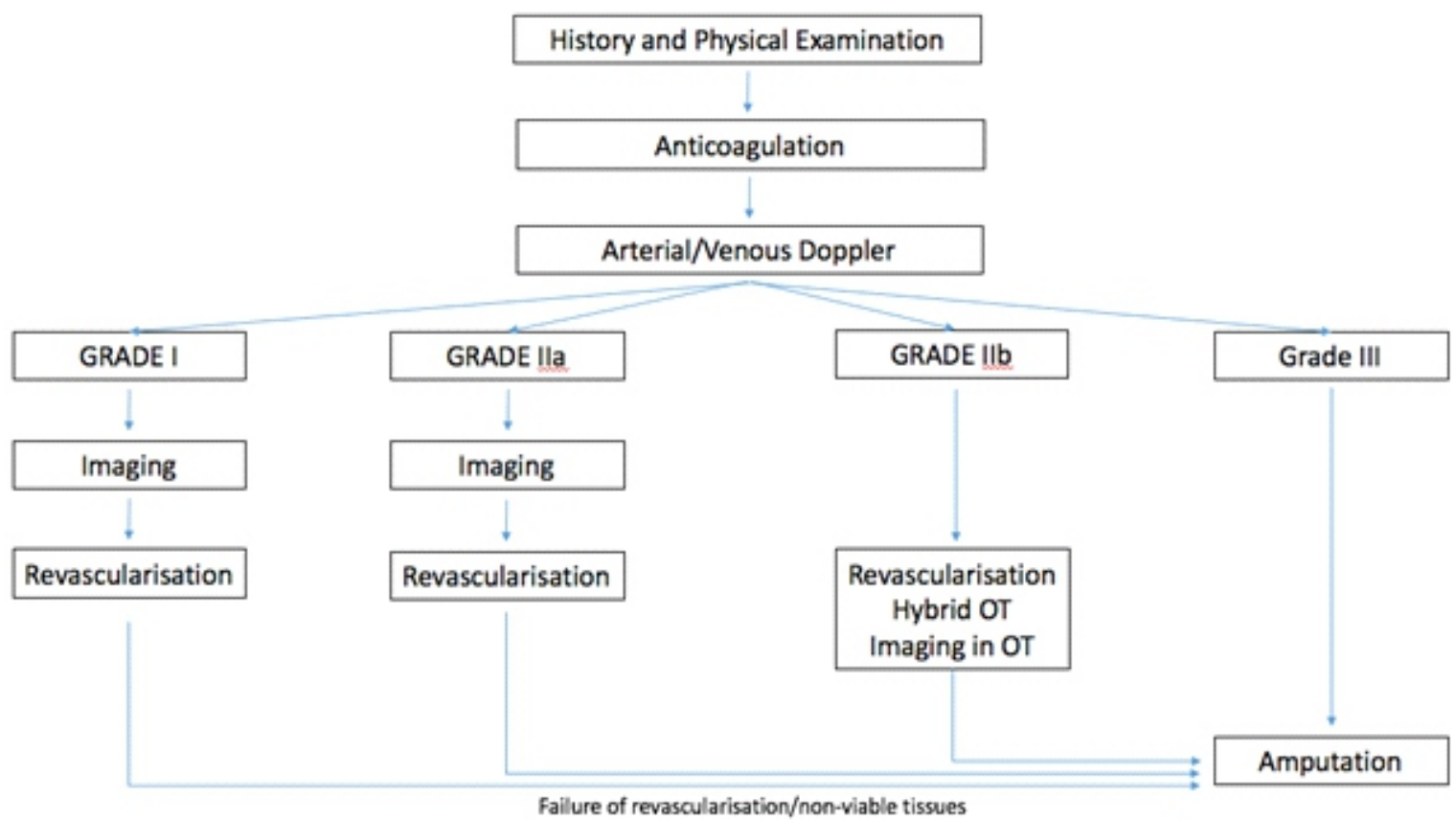

Figure 1. Algorithm for the investigation and treatment of ALI. Adapted from Norgren et al 2007 (TASC II). OT, operating theatre.

Although subcutaneous low molecular weight heparin (LMWH) offers practical advantages and is widely used, there is currently no high level evidence supporting its use.

\section{Thrombolysis}

Berridge et al reviewed five randomized controlled trails comparing systemic thrombolysis and surgery in acute ischaemic limb [5-7]. The review concluded that there was no clear superiority of either treatment over another with limb

\section{Box 2 Contraindications to thrombolysis}

- Stoke within 2 months

- Acute haemorrhage

- Recent gastrointestinal bleed within 10 days

- Recent neurosurgery

- Intracranial trauma/lesion / aneurysm

- Recent surgery

- Uncontrolled hypertension

- Pregnancy salvage or mortality but major complications were more common with thrombolysis. There has been a decrease in the use of systemic thrombolysis due to concerns about efficacy and serious complications, Box 2 [8].

\section{Grade I Viable \& Grade IIa Threatened Salvageable with prompt intervention}

Other than established surgical techniques (Box 3) emerging percutaneous endovascular interventions warrant consideration this group of patients although high level evidence to support their use remains sparse.

\section{Catheter Directed Thrombolysis (CDT)}

Regional thrombolytic therapy is delivered through an intraarterial catheter within the thrombus. This reduces systemic distribution of thrombolytic agents. Compared to balloon catheter embolectomy there is a reduced risk of endothelial trauma and thrombolysis occurs in smaller branch vessels otherwise inaccessible to the balloon. 
monitoring and its dependence on intravenous access. Although subcutaneous low molecular weight heparin (LMWH) offers practical advantages and is widely used, there is currently no high level evidence supporting its use.

\section{Thrombolysis}

Berridge et al reviewed five randomized controlled trails comparing systemic thrombolysis and surgery in acute ischaemic limb [5-7]. The review concluded that there was no clear superiority of either treatment over another with limb salvage or mortality but major complications were more common with thrombolysis. There has been a decrease in the use of systemic thrombolysis due to concerns about efficacy and serious complications, Box 2 [8].

\section{Grade I Viable \& Grade IIa Threatened Salvageable with prompt intervention}

Other than established surgical techniques (Box 3) emerging percutaneous endovascular interventions warrant consideration this group of patients although high level evidence to support their use remains sparse.

\section{Catheter Directed Thrombolysis (CDT)}

Regional thrombolytic therapy is delivered through an intra-

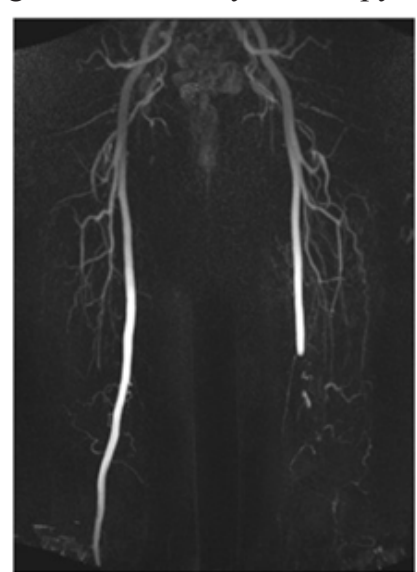

A

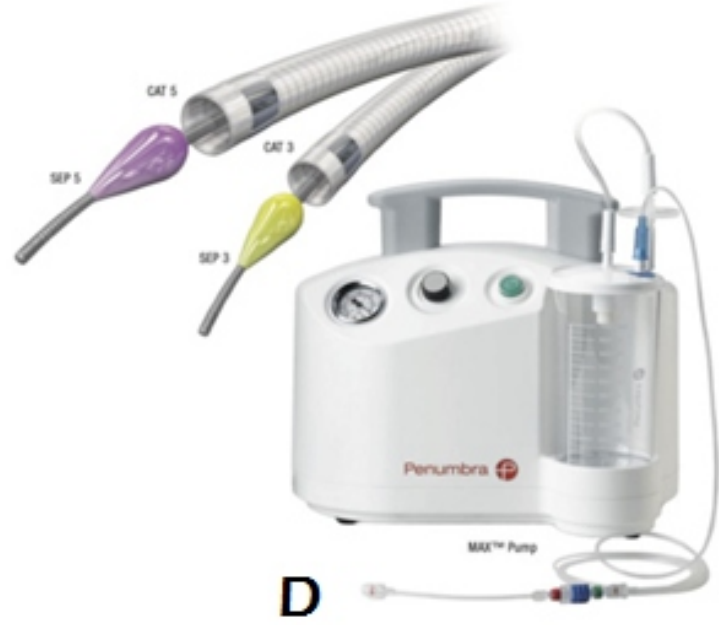

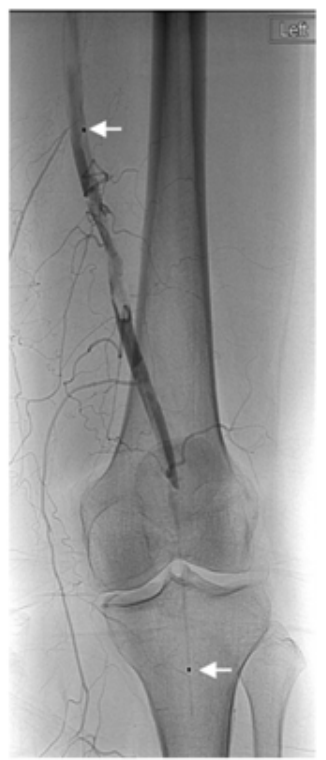

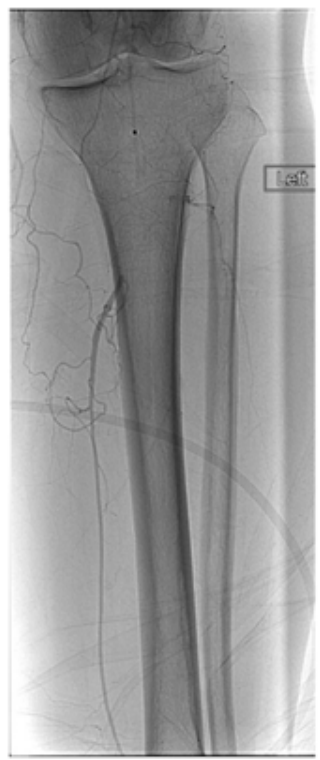

C
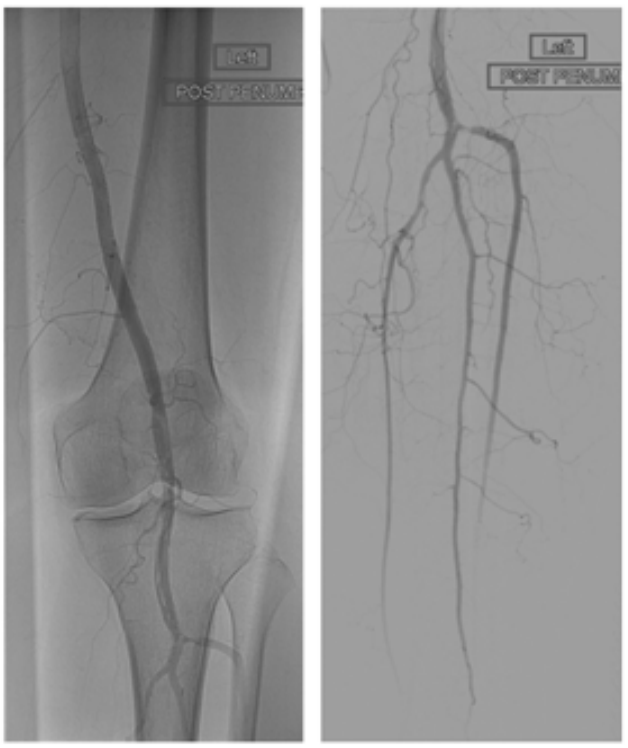

E arterial catheter within the thrombus. This reduces systemic distribution of thrombolytic agents. Compared to balloon catheter embolectomy there is a reduced risk of endothelial trauma and thrombolysis occurs in smaller branch vessels otherwise inaccessible to the balloon.

However, its use is limited by the availability of endovascular facilities, need for critical care, high costs, long duration required for the resolution of the thrombus and risks of bleeding and distal embolism [9].

Percutaneous Aspiration Thrombectomy (PAT)

This technique involves using large lumen aspiration catheters attached to suction with a syringe to remove

The Sri Lanka Journal of Surgery 2017; 35(1): 10-14 
thrombo-embolic material (Pronto extraction catheter [Vascular Solutions, Inc., Minneapolis, MN], Export catheter [Medtronic, Inc., Minneapolis, MN]. This can be used in combination with thrombolytics to reduce required dose and increase speed of therapy [10]. The Penumbra System (PS; Penumbra, Alameda, California) offers the ability to both aspirate and extract material, Figure 2.

\section{Percutaneous Mechanical Thrombectomy (PMT)}

PMT utilises hydrodynamic or rotational systems to mechanically disrupt and aspirate thromboembolic material. This is useful for patients with high perioperative risks who are unsuitable for CDT. PMT is most effective for fresh thromboembolic material although some rotational devices are suitable for organised clots $<6$ months old. Complications

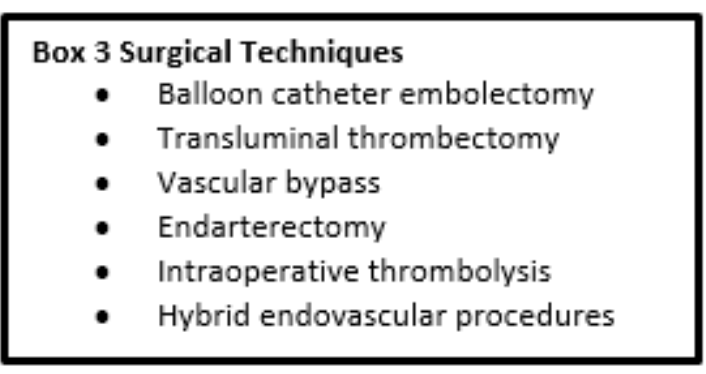

include distal embolization, fluid overload and the systemic effects of haemolysis. Some of these limitations are addressed by isolated pharmacomechanical thrombolysisthrombectomy (IPMT) systems although they are not in widespread use [11].

Figure 2 Endovascular treatment of acute limb ischaemia (ALI). Diagnostic images of a 71 year old female with breast cancer and left leg ALI. A, Magnetic resonance angiography (MRA) and B conventional digital subtraction angiography were performed and revealed superficial femoral artery (SFA) occlusion. Catheter directed thrombolysis (CDT) was performed using a fountain catheter for 24 hours with some improvement on check angiography, C (arrow heads proximal and distal limits of the infusion catheter). An underlying lesion was stented in the SFA and the Penumbra TM aspiration and extraction system (Alameda, California) D was used to remove thromboembolic material and provided excellent three vessel distal run-off, $\mathrm{E}$.

\section{Grade IIb Salvageable with immediate intervention}

\section{Surgery}

Rutherford IIb patients generally require surgery although selected high risk patients may be managed with endovascular treatment. Factors to consider are anatomical location (open approach for supra inguinal and femoral bifurcation vs. endovascular techniques for popliteal trifurcation or distal lesions), nature of occlusion, duration of symptoms and the availability of endovascular resources.
Access for surgical revascularisation should be planned in accordance with the location of the lesion. Femoral or popliteal approaches may be used to deploy a range of surgical techniques, Box 3 .

Surgical result for infrainguinal balloon thrombectomy is generally poor, and bypass grafting may be more suitable. Endovascular therapy allows for imaging of underlying disease once the acute thrombosis is treated. This would facilitate assessment for further management. Similarly, completion angiography is performed in surgical revascularisation after clot retrieval to assess for underlying disease as well as residual occlusions.

In cases of late presentation diagnostic fasciotomies to assess tissue viability prior to attempted revascularisation is a useful approach. If deemed non-viable then amputation can be performed directly. Otherwise, prophylactic fasciotomies should be considered for those with prolonged periods of ischaemia, following complex procedures or after measurement of compartment pressures.

\section{Grade III Irreversible major tissue loss or nerve damage inevitable}

Amputation

\begin{tabular}{|l|l|}
\hline Dehydration & Sepsis, gastroenteritis, diabetes \\
\hline Hypotension & $\begin{array}{l}\text { Cardiogenic - infarction, arrhythmia } \\
\text { Haemorrhage }\end{array}$ \\
\hline Malignancy & Increasingly common \\
\hline Hyperviscosity & $\begin{array}{l}\text { Haematological - thrombocytosis, } \\
\text { polycythaemia }\end{array}$ \\
\hline Thrombophilia & $\begin{array}{l}\text { Protein C/S \& Anthithrombin III } \\
\text { deficiency, Activated Protein C resistance, } \\
\text { Factor V Leiden, Anti-phospholipid }\end{array}$ \\
\hline
\end{tabular}

Table 2. Predisposing factors for acute thrombotic acute limb ischaemia. Adapted from Callum et al 2000.

Amputation is generally performed in the first instance if the patient has grade III ALI or following failure of revascularisation. Guillotine amputation may be performed if sepsis is present to minimise procedural time. Imaging is generally not required as the level of amputation is determined by clinical and intraoperative findings. Although promising in laboratory research no adjuncts are routinely available to determine the level of amputation (transcutaneous blood flow or oxygen pressures, thermometry, doppler or contrast enhanced imaging / angiography). Amputations should be performed within 48 hours from decision to operate, unless new medical contraindications arise [12]. 


\section{Palliative}

It is important to recognise ALI may be a pre-terminal event where aforementioned interventions are futile. Decisions to palliate should be made through a multidisciplinary approach with involvement of the patient, family, carers and with consideration to interventional risk and its effect on the patient's quality of life [13].

\section{Source identification}

If thrombosis has occurred at a site of pre-existing stenosis precipitating causes should be excluded, Table 2. Around $80 \%$ of embolic ALI will be from atrial thrombus associated with AF but other sources include the left ventricle, coronary valves, proximal aneurysmal disease (popliteal, abdominal/thoracic aorta), prosthetic grafts, paradoxical embolus and atrial myxoma. Echocardiography \pm bubble studies, 24 hour ECG recording and cross sectional imaging will detect most underlying pathologies. $15 \%$ will remain idiopathic [14].

\section{Secondary Prevention}

Those with thrombotic ALI should continue on best medical therapy, receive advice on smoking cessation and supervised exercise programmes for the underlying PAD [15]. All patients should receive anticoagulation post operatively to prevent recurrent thromboembolism. The duration of treatment vary according to the underlying cause. Those with an underlying thrombophilia or embolic ALI should be anticoagulated long term if appropriate $[1,11,16]$.

\section{Future Directions}

Hybrid endovascular theatres hold promise for facilitating timely combined open and endovascular approaches as will dual trained vascular practitioners. The use of novel oral antiplatelets and anti-coagulants (NOAC) for PAD are currently being explored in randomised controlled clinical trials.

All authors disclose no conflict of interest. The study was conducted in accordance with the ethical standards of the relevant institutional or national ethics committee and the Helsinki Declaration of 1975, as revised in 2000 .

\section{References}

1. Norgren L, Hiatt WR, Dormandy JA, Nehler MR, Harris KA, Fowkes FG. Inter-Society Consensus for the Management of Peripheral Arterial Disease (TASC II). J Vasc Surg. 2007;45 Suppl S:S5-67. https://doi.org/10.1016/j.jvs.2006.12.037

2. Hirsch AT, Criqui MH, Treat-Jacobson D, Regensteiner JG, Creager MA, Olin JW, et al. Peripheral arterial disease detection, awareness, and treatment in primary care. Jama. 2001;286(11):1317-24

https://doi.org/10.1001/jama.286.11.1317

3. Rutherford RB, Baker JD, Ernst C, Johnston KW, Porter JM, Ahn S, et al. Recommended standards for reports dealing with lower extremity ischemia: revised version. J Vasc Surg.

1997;26(3):517-38.

https://doi.org/10.1016/S0741-5214(97)70045-4

4. Horlocker TT. Regional anaesthesia in the patient receiving antithrombotic and antiplatelet therapy. Br J Anaesth. 2011;107 Suppl 1:i96-106. https://doi.org/10.1093/bja/aer381

5. Berridge DC, Kessel D, Robertson I. Surgery versus thrombolysis for acute limb ischaemia: initial management. Cochrane Database Syst Rev. 2000(4):Cd002784. https://doi.org/10.1002/14651858.CD002784

6. Ouriel K, Veith FJ, Sasahara AA. A comparison of recombinant urokinase with vascular surgery as initial treatment for acute arterial occlusion of the legs. Thrombolysis or Peripheral Arterial Surgery (TOPAS) Investigators. $N$ Engl J Med. 1998;338(16):1105-11. https://doi.org/10.1056/NEJM199804163381603

7. Results of a prospective randomized trial evaluating surgery versus thrombolysis for ischemia of the lower extremity. The STILE trial. Ann Surg. 1994;220(3):251-66; discussion 66-8. https://doi.org/10.1097/00000658-199409000-00003

8. Richards T, Pittathankal AA, Magee TR, Galland RB. The current role of intra-arterial thrombolysis. Eur J Vasc Endovasc Surg. 2003;26(2):166-9. https://doi.org/10.1053/ejvs.2002.1915

9. Nachbur B, Baumgartner I, Do D, Mahler F, Ris H-B. Acute Limb Ischaemia: Endovascular Options. In: Barros D'Sa A, Chant A, editors. Emergency Vascular and Endovascular Practice. Second ed. London: Hodder Arnold; 2005. p. 181-95. https://doi.org/10.1201/b13193-24

10. Zafar N, Prasad A, Mahmud E. Utilization of an aspiration thrombectomy catheter (Pronto) to treat acute atherothrombotic embolization during percutaneous revascularization of the lower extremity. Catheter Cardiovasc Interv. 2008;71(7):972-5. https://doi.org/10.1002/ccd.21561

11. Creager MA, Kaufman JA, Conte MS. Clinical practice. Acute limb ischemia. NEngl J Med. 2012;366(23):2198-206. https://doi.org/10.1056/NEJMcp1006054

12. The Vascular Society of Great Britain and Ireland Quality Improvement Framework for Major Amputation Surgery. Vascular Society of Great Britain and Ireland. 2010. Available from: https://www.vascularsociety.org.uk

13. Campbell WB, Verfaillie P, Ridler BM, Thompson JF. Nonoperative treatment of advanced limb ischaemia: the decision for palliative care. Eur J Vasc Endovasc Surg. 2000;19(3):246-9. https://doi.org/10.1053/ejvs.1999.1052

14. Callum K, Bradbury A. ABC of arterial and venous disease: Acute limb ischaemia. Bmj. 2000;320(7237):764-7. https://doi.org/10.1136/bmj.320.7237.764

15. National Institute for Health and Care Excellence. NICE Guidelines CG147: Lower limb peripheral arterial Available from: https://www.nice.org.uk/guidance/CG147

16. Alonso-Coello P, Bellmunt S, McGorrian C, Anand SS, Guzman $\mathrm{R}$, Criqui $\mathrm{MH}$, et al. Antithrombotic therapy in peripheral artery disease: Antithrombotic Therapy and Prevention of Thrombosis, 9th ed: American College of Chest Physicians Evidence-Based Clinical Practice Guidelines. Chest. 2012;141(2 Suppl):e669S90S.

https://doi.org/10.1378/chest.11-2307 